\title{
OPERATIONAL SERVICE FOR THE DETECTION OF VESSELS AND MARITIME ACTIVITIES WITH OPTICAL SATELLITE IMAGERY IN NEAR REAL TIME - EXPERIENCES AND FUTURE ASPECTS
}

\author{
Enrico Stein ${ }^{1}$, Robin Nitsche ${ }^{1}$, Dr. Konstanze Lechner ${ }^{1}$, Egbert Schwarz ${ }^{2}$, Matthias \\ Berg², Ralph Kiefl' ${ }^{1}$, Dr. Rupert Mülller ${ }^{1}$ \\ ${ }^{1}$ German Aerospace Center (DLR), Earth Observation Center, Münchner Str. 20, 82234 Weßling, Germany \\ 2 German Aerospace Center (DLR), Earth Observation Center, Kalkhorstweg 53, 17235 Neustrelitz, Germany
}

In the context of the project OpSSERVE - Optical Satellite Services for EMSA (European Maritime Safety Agency) - the European Space Imaging (EUSI) and the German Aerospace Center (DLR) established for the first time a fully operational and near real-time service to detect vessel and maritime activities using high resolution optical satellite imagery. The service was implemented in 2013 and contribute to maritime situational awareness, e.g. in order to reduce the risk of maritime accidents, marine pollution and the loss of human life at sea.

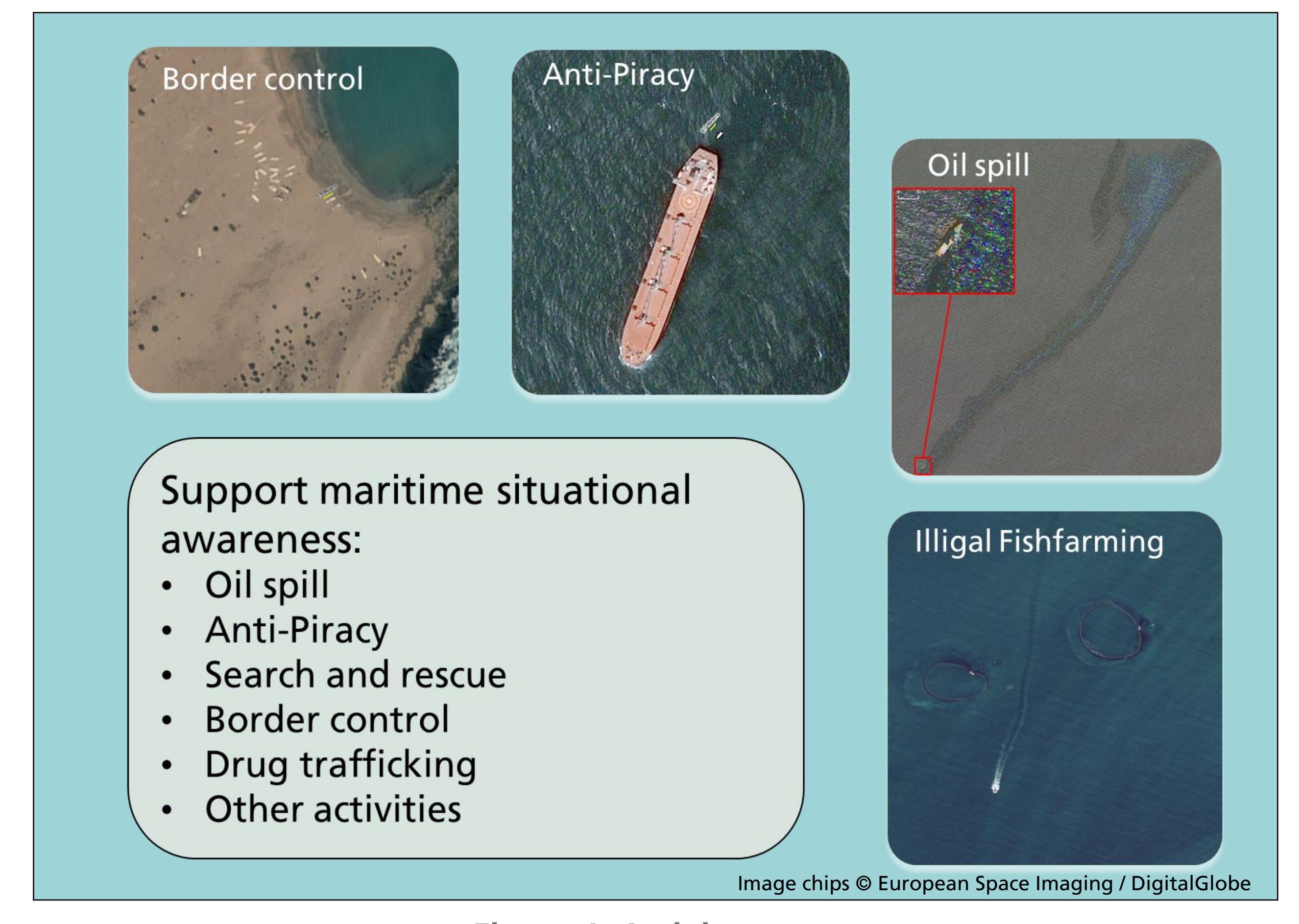

Figure 1: Activity types

2007 the EMSA established the CleanSeaNet (CSN) system to provide pollution detection services in support of maritime surveillance and decision making for all participating European member states based on SAR satellite imageries. The main advantage of SAR data is their independence of weather conditions (cloud coverage), but depend on the image resolution and target backscatter the identification of small vessels is rather difficult. The use of very high resolution (VHR) optical data provides valuable information to identify small vessels $(\leq 15 \mathrm{~m})$ From the VHR optical imagery, actionable information products are created in an automatic processing chain including image preprocessing, data transcription, automatic vessel detection, supervised interactive vessel and activity detection and finally the delivery of standardized products to EMSA. The service provides access to globally collected satellite imageries and enables value adding services in near real-time (1 or 3 hours).

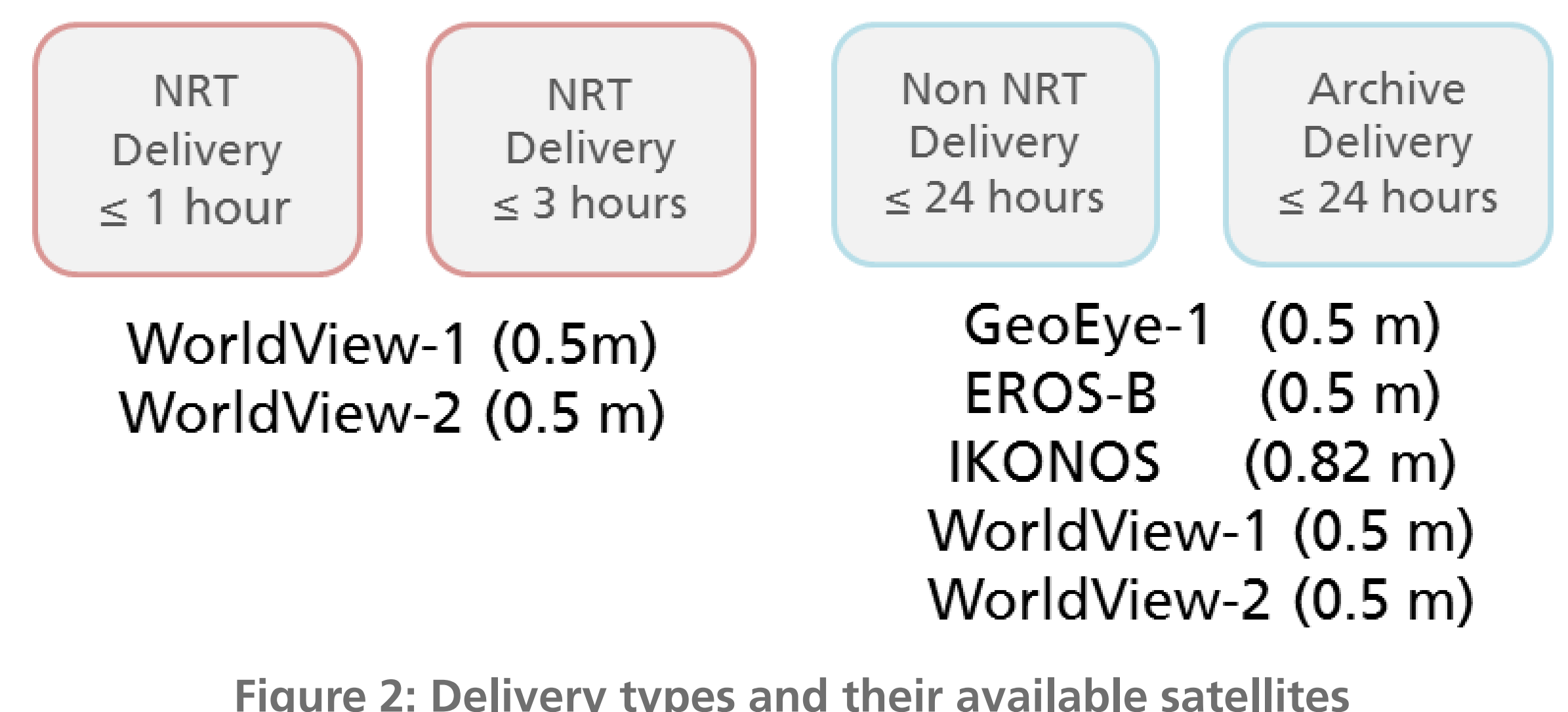

In a case of a request of the EMSA a feasibility check is necessary by EUSI whether a satellite tasking is possible. After the confirmation the image acquisition, the data download and a standard processing with a radiometric correction, a orthorectification and a pan-sharpening is executed. Finally the transfer to DLR ftp pick-up-point in 15 min to 35 min (worst case) is performed. The L1b image data are transcribed to a semi-automatic processing chain at DLR (parallel in the sense of multithreading and asynchron process scheduling) and delivered to EMSA.

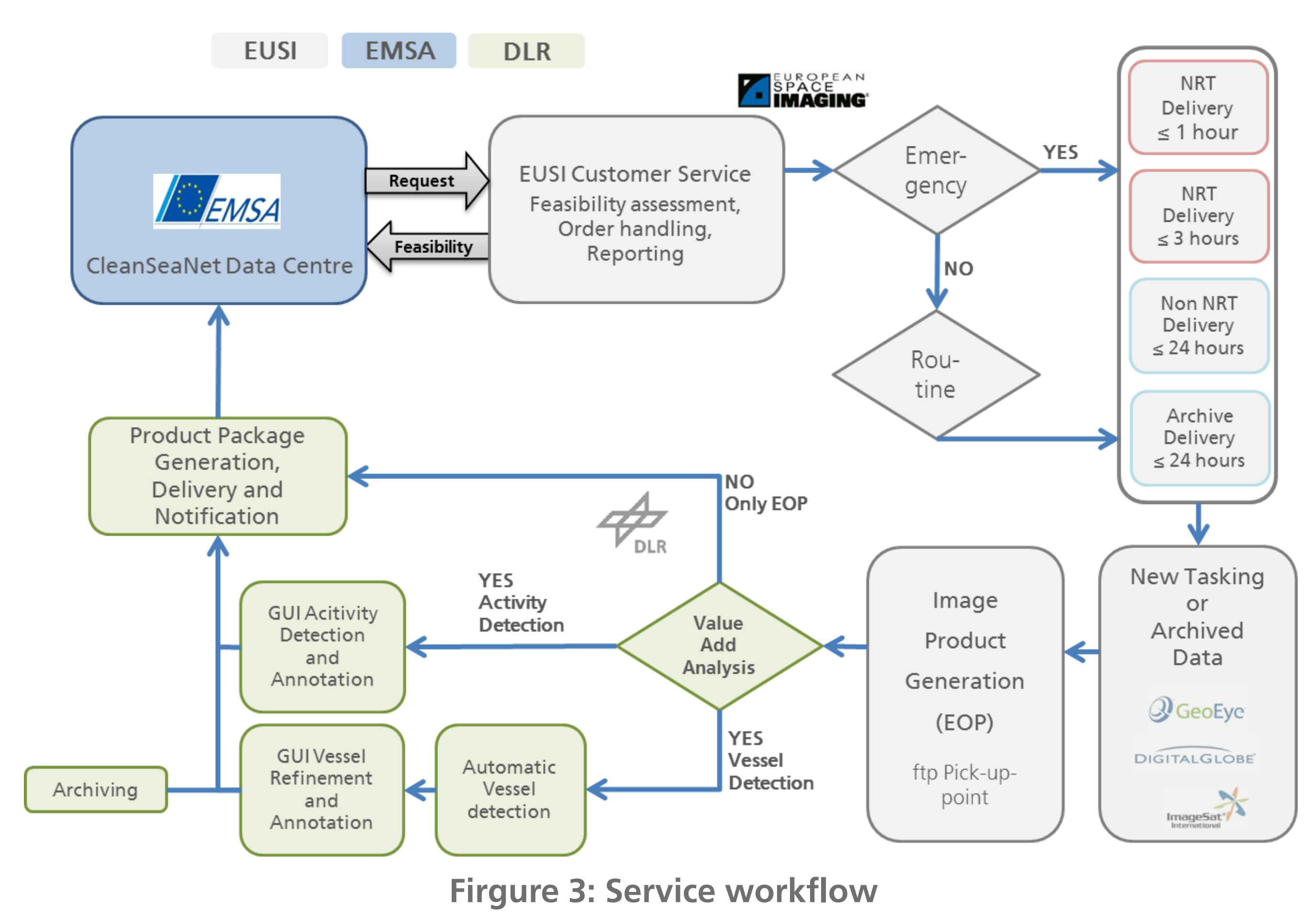

The operator supervision is performed by using a graphical user interface (GUI). The GUI application has been developed embedded in the Java based NASA World Wind. The product supervision is accomplished with the functionalities like removing, adding, adapting detected vessels based on the satellite image and the results of the automatic vesse detection. Furthermore the application supports the identification of vessel and activity types, completed with the confidence level.

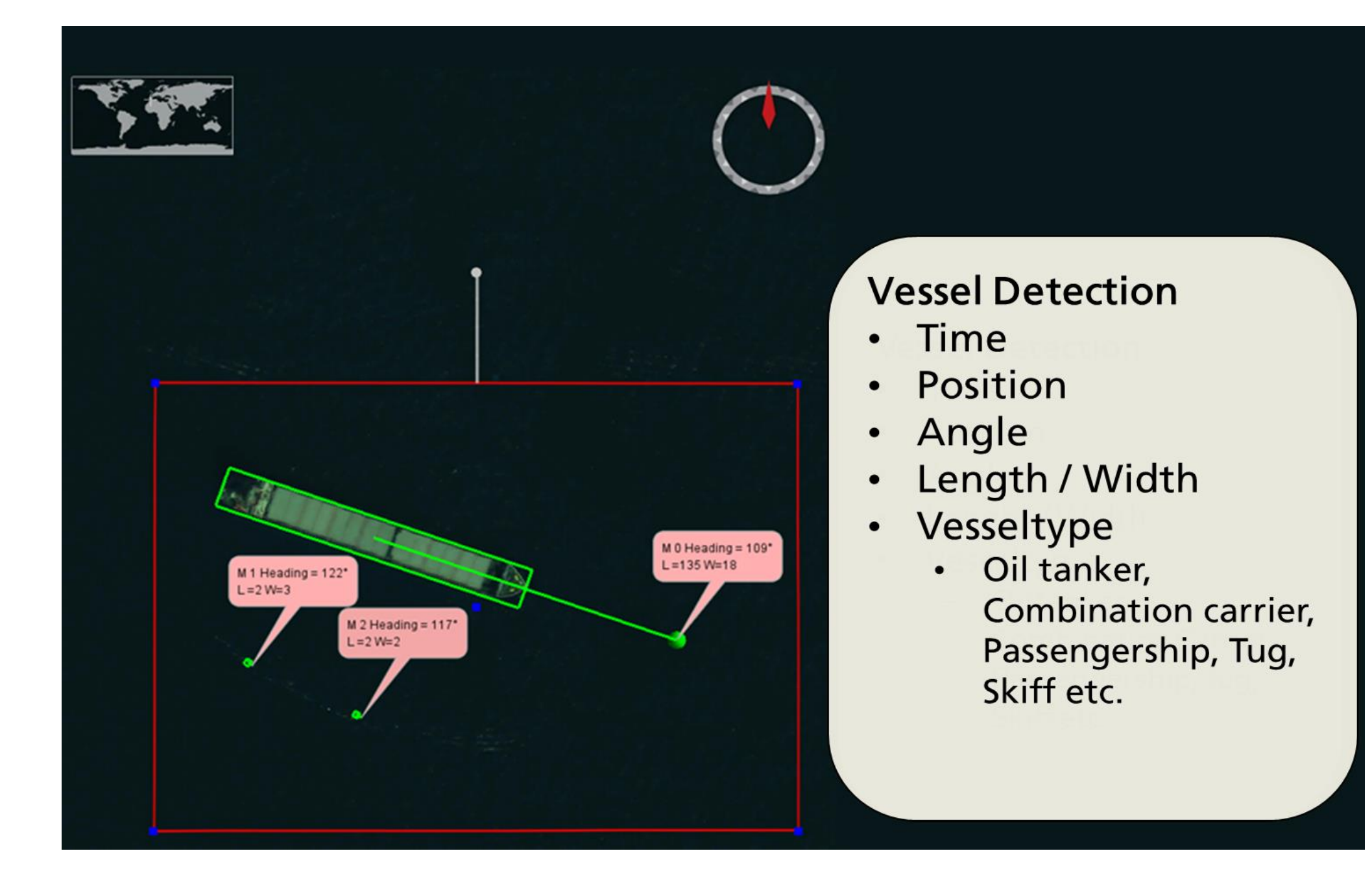

Figure 4: GUI - Vessel detection interface and the different types

Since the beginning of the project in 2013 the service was used more than 100 times and about 800 vessels were detected. In order to optimize the near real time framework the service and the GUI were improved with:

User friendly enhancements like 2/3-D view

Parallel processing of products (vessel detection / activity detection product)

Integration of WorldView-3

Image access based on GeoServer
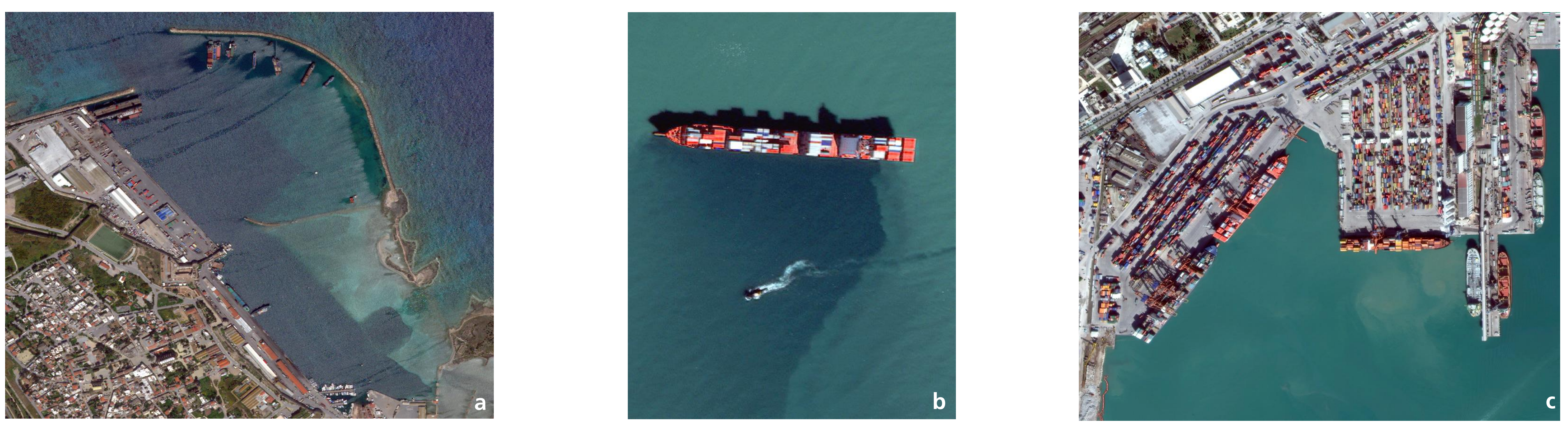

Figure 5: Image examples: a) Harbour of Famagusta - WorldView-2, 05/04/2015; b) Container ship (about $230 \mathrm{~m}$ long) - WorldView-2, 27/02/2015; Harbour of Mersin - WorldView-2, 21/02/2015 @ European Space Imaging 